\title{
Development of the gonad in normal and anencephalic human fetuses
}

\author{
T. G. Baker* and J. B. Scrimgeour \\ Department of Obstetrics and Gynaecology, University of Edinburgh, 23 Chalmers Street, \\ Edinburgh $E H 39 E W, U . K$.
}

\begin{abstract}
Summary. The development of the germinal and somatic cells in the gonads of normal and anencephalic fetuses was investigated. Interstitial cells were reduced in number in both sexes and in males the population of gonocytes in profiles of seminiferous tubules was reduced when Leydig cells were seemingly absent. Ovarian differentiation up to about 34 weeks after conception was apparently normal, although precise counts of the numbers of germ cells were not carried out. Nevertheless, oogonia increased in number by mitotic divisions, oocytes progressed through meiotic prophase to the diplotene stage, and primordial follicles formed normally. By contrast, 'growing' and small antral follicles, which are a constant feature of control ovaries, were not observed in the anencephalic specimens.
\end{abstract}

\section{Introduction}

Most studies on the pre-natal development of the mammalian gonad have been concerned with qualitative or quantitative investigations of oogenesis and follicular growth or with analyses of the chromosomal configuration of oocytes at various stages of meiotic prophase (see Baker, 1972b; Franchi \& Baker, 1973; Zuckerman \& Baker, 1977). Although much information has been obtained from these studies, little is known about the factors that control the initiation of oogenesis, the progression of oocytes through meiotic prophase and their arrest at the diplotene stage, and the onset of follicular growth around the time of birth. The limited available information on these controlling mechanisms derives largely from studies involving organ culture of embryonic and fetal gonads, removal of the maternal or fetal pituitary gland, or from treatment of neonatal mice with antisera to gonadotrophic hormones.

These investigations indicate that gonadotrophins have little or no effect on the mitotic division of oogonia, on the progression of oocytes through meiotic prophase to the diplotene (so-called 'resting') stage, or on the formation of primordial follicles (see Baker \& Neal, 1973, 1975; Challoner, 1975a, b). By contrast, follicle-stimulating hormone (FSH), and possibly luteinizing hormone (LH), may influence the total number of germ cells (and the proportion undergoing degeneration before birth: Gulyas, Hodgen, Tullner \& Ross, 1977a), and the initiation of follicular growth beyond the primordial stage (Eshkol, Lunenfeld \& Peters, 1971; Baker \& Neal, 1973; Challoner, 1975a, b). However, these results clearly need to be confirmed by using a suitable in-vivo model, instead of gonads obtained by some of the procedures listed above.

The anencephalic human fetus provides a suitable 'natural' model in which to assess the role of the hypothalamic-hypophysial system in the initiation of oogenesis and follicular growth in

* Present address: School of Studies in Medical Sciences, University of Bradford, Bradford, West Yorkshire BD7 1DP, U.K. 
vivo, and yet there has been little study of events in the gonad or of the differentiation of germ cells. The few published reports are usually concerned with the overall anencephalic syndrome, although they often include cursory remarks to the effect that the gonads are reduced in size (as compared with those of coeval controls) and that the number of interstitial cells in the ovaries and testes of anencephalic fetuses is considerably reduced (see below). Only Ch'in (1938) has reported on any of the follicular or germinal cell stages.

The purpose of the present study was to (1) re-examine the development of the gonad in anencephalic and normal fetuses in the light of current hypotheses on the control of oogenesis and follicular growth; (2) to review these results in terms of earlier reports on anencephaly; and (3) to take advantage of a unique opportunity of studying human gonadal development. It is necessary to describe first the anatomical features of the anencephalic fetus.

\section{The anencephalic syndrome}

Anencephaly is a major congenital malformation resulting from the failure of the vault of the skull to form during embryonic development. Subsequently the brain probably becomes eroded or seriously damaged and the affected fetuses are aborted, born prematurely, or die shortly after birth (Browne, 1920; Nakano, 1973). The cause of anencephaly is unknown but its distribution throughout the world varies with race and social class from a nadir of 0.2 per 1000 deliveries in Norway to a zenith of 4-8 per 1000 births in Belfast and Dublin (Lemire, Beckwith \& Warkany, 1978). The incidence in the Edinburgh area of Scotland is 2.8 per 1000 deliveries (Elwood, 1970; Elwood \& MacKenzie, 1971) and females are more commonly affected than males such that in Edinburgh the percentage of anencephalic males is close to the $30 \%$ of total affected births reported by MacMahon \& McKeown (1952).

The anencephalic fetus is characterized by the absence of the cranium, almost total destruction of the cerebrum and cerebellum, protruding eyes and tongue, obesity, various skeletal abnormalities (particularly affecting the limbs), and is often associated with various degrees of spina bifida (Browne, 1920; Nakano, 1973; Lemire et al., 1978). Most authors believe that the hypothalamus and posterior lobe of the pituitary gland are absent from anencephalic fetuses, and Ch'in (1938) considered that the pars intermedia was lacking in $98 \%$ of his specimens. The anterior lobe of the pituitary is generally reduced in size (Browne, 1920; Ch"in, 1938; Nakano, 1973). Studies with the electron microscope have shown that the pars anterior of the pituitary in the anencephalic contains thyrotrophs, somatotrophs and gonadotrophs with seemingly normal secretory granules within them (Salazar, MacAulay, Charles \& Pardo, 1969). These secretory granules may well represent TSH, FSH, LH and ACTH, although the release of these hormones would be impaired in the absence of the hypothalamus and its releasing factors. Certainly the target organs of these hormones (thyroid, ovary, testis and adrenal) are considerably reduced in size and there is evidence that at least some of their steroid hormones are reduced or even absent (see Michie, 1966; Nakano, 1973). Indeed, the human fetal testis in anencephaly contains few androgen-producing Leydig cells (Zondek \& Zondek, 1965), and the low oestriol production by the feto-placental unit has been used as an aid in the diagnosis of anencephaly (Frandsen \& Stakemann, 1961; Michie, 1966).

\section{Materials and Methods}

The material consisted of 16 female and 9 male anencephalic fetuses, 12 female and 10 male control fetuses collected at the same time, and the control fetuses collected by Baker (1963 and unpublished results; see Table 1). Most of the fetuses and neonates were subject to routine post-mortem examination by pathologists at the Royal Hospital for Sick Children in Edinburgh (present material) or the Children's Hospital in Birmingham (Bakerr's 1963 material) 
Table 1. Age of the human fetal gonads used in the study

\begin{tabular}{|c|c|c|c|c|c|c|}
\hline \multirow{3}{*}{$\begin{array}{c}\text { Age } \\
\text { (weeks p.c.) }\end{array}$} & \multirow{2}{*}{\multicolumn{2}{|c|}{ Anencephalic gonads }} & \multicolumn{4}{|c|}{ Normal gonads } \\
\hline & & & \multicolumn{2}{|c|}{ Present material } & \multicolumn{2}{|c|}{ Other materia } \\
\hline & $\hat{o}$ & q & $\delta$ & $q$ & $\hat{O}^{* *}$ & ot \\
\hline $10-18$ & 1 & 1 & 3 & 3 & 5 & 5 \\
\hline $20-25$ & 3 & 2 & 1 & 4 & 1 & 5 \\
\hline $26-29$ & 2 & 4 & 1 & 4 & 2 & 4 \\
\hline $30-33$ & 1 & 5 & 1 & 1 & 4 & 4 \\
\hline 34-term & 2 & 4 & 3 & 3 & 8 & 4 \\
\hline
\end{tabular}

The gestational ages of the normal fetuses were assessed from crown-rump length and the date of the last menstrual period recorded by the mother (see Baker, 1963). For the anencephalic fetuses only the menstrual histories of the mother could generally be used since the vault of the skull was absent and the brain too severely damaged to permit crown-rump length to be accurately assessed. Nevertheless, lack of agreement between gross size and menstrual age necessitated the rejection of a further 3 female anencephalic fetuses from this study.

In both the present series of specimens, and those collected by Baker (1963), the gonads were cleanly dissected from the fetuses and were fixed in Bouin's aqueous fluid, usually within $8 \mathrm{~h}$ of death: however, a few were not recovered for a further $24 \mathrm{~h}$ and some autolytic changes were evident in these specimens. Most of the gonads were serially sectioned at a thickness of 5-7 $\mu \mathrm{m}$, although for others only a few representative sections cut at the same thickness were available. After staining with haematoxylin and eosin, or with Azan, the sections were examined and photographed for the developmental stage attained by the germinal and somatic cells.

\section{Results}

\section{Development of the testis in normal and anencephalic fetuses}

The normal human testis increases dramatically in size during fetal life but the histology of the seminiferous tubules presents a fairly uniform picture throughout pregnancy (Pl. 1, Fig. 1). These tubules have well-defined basal laminae and contain abundant gonocytes and somatic cells (so-called pro-Sertoli cells). Interspersed between the seminiferous tubules are islands of Leydig (interstitial) cells (Pl. 1, Fig. 1), the number of which varies with the stage of gestation and in particular with the blood concentrations of chorionic gonadotrophin (hCG: Abramovich, Baker \& Neal, 1974).

By contrast, in its most extreme condition anencephaly was characterized by such a marked reduction (if not complete absence) of Leydig tissue that seminiferous tubules were in close apposition (Pl. 1, Fig. 2). The tubules themselves appeared to be superficially similar to those in controls, although the number of gonocytes (pre-spermatogonia) in cross-sections of the tubules appeared to be much lower than in those of coeval controls (Pl. 1, Fig. 2; cf. Pl. 1, Fig. 1).

In other anencephalic fetuses damage to the testis was less severe and a gradation of effects was observed. Some specimens contained a few Leydig cells and a seemingly normal population of gonocytes (Pl. 1. Figs 1, 2 and 3), while others possessed areas of intertubular connective tissue where in controls islands of Leydig cells would normally be seen (see Pl. 1, Fig. 4). When the Leydig cells were apparently absent the number of gonocytes was also reduced (Pl. 1, Figs 1, 2 and 4$)$.

The extent of the lesion within the fetal testis appeared to be related either to the extent of 
damage in the hypothalamus, or to the time when this damage became manifest, although neither we nor Ch'in (1938) were usually able to examine the hypothalamus and pituitary glands in the anencephalic fetuses.

\section{Development of the normal ovary}

Once the process of sexual differentiation of the gonad has been completed (about Day 44 p.c.) the ovary consists of a series of epithelial cords (seemingly originating from the coelomic epithelium and the mesonephros) containing the primordial germ cells. The latter (now called oogonia) rapidly undergo mitotic division and their number greatly increases to about 600000 by the 8th week of gestation (Baker, 1971). From the 10th week p.c. onwards an ever increasing proportion of these germ cells enter meiotic prophase while the remainder continue to proliferate by mitosis. Thus by the 20th week p.c. the maximum population of germ cells is recorded (Text-fig. 1) and consists of oogonia (both 'resting' and dividing), together with oocytes at all stages of meiotic prophase up to the diplotene stage (Pl. 2, Fig. 5; Baker, 1963, 1972b; van Wagenen \& Simpson, 1965). Oocytes at the diplotene stage of meiotic prophase are encountered first during the 4th month of gestation but primordial follicles remain few in number until the late 5th month or early 6th month of gestation. The proportion of follicular oocytes gradually increases at the expense of the pre-diplotene stages which either degenerate or progress to the diplotene stage. Primordial follicles are initially located close to the cortico-medullary boundary but by the time of birth only a thin rim of pre-follicular germ cells is encountered, and this is eliminated shortly after birth (van Wagenen \& Simpson, 1965). Between the 34th week after conception and the time of birth multilayered and even antral follicles are frequently seen within the ovary (Pl. 2, Fig. 6; Potter, 1963; Baker, 1972a, b).

\section{Development of ovaries in anencephalic fetuses}

In view of the marked differences found in the development of the testis in anencephalic fetuses it was perhaps surprising that ovarian development was almost identical in the ovaries of anencephalic and control fetuses up to and including the 7th month of gestation. The youngest specimen available for study was aged 10 weeks p.c. and contained oogonia ('resting' and dividing) and oocytes at the leptotene and zygotene stages of first meiotic prophase (Pl. 2, Fig. 7). The histological appearance of this specimen was therefore wholly consistent with that of coeval controls, although precise counts of the germ cells would be required to detect changes in the populations of oogonia and oocytes, and the extent of germ cell degeneration.

The ovaries of a 26-week old anencephalic fetus were also similar to those of controls (P1. 2, Fig. 8) in that germ cells at all stages up to the diplotene stage of meiotic prophase were encountered. The distribution of primordial follicles in ovaries recovered between the 32 nd week p.c. and full term was also similar in the two groups, although there was an indication that the primordial follicles were more scattered throughout the cortex of the anencephalics, compared to the fairly regular cortico-medullary distribution in controls (PI. 2, Fig. 8; Pl. 3, Fig. 9). However, there were no 'growing' or antral follicles (Text-fig. 2) in the anencephalic fetuses (Pl. 3, Fig. 10; cf. Pl. 2, Fig. 6).

\section{Discussion}

The results of the present study confirm earlier observations that the size of the gonad and the quantity of interstitial cells are considerably reduced in anencephalic fetuses, although the extent of the latter effect varies considerably between specimens (Zondek \& Zondek, 1965). Our results for depletion of interstitial cells in the ovary need to be confirmed on a large series of specimens 

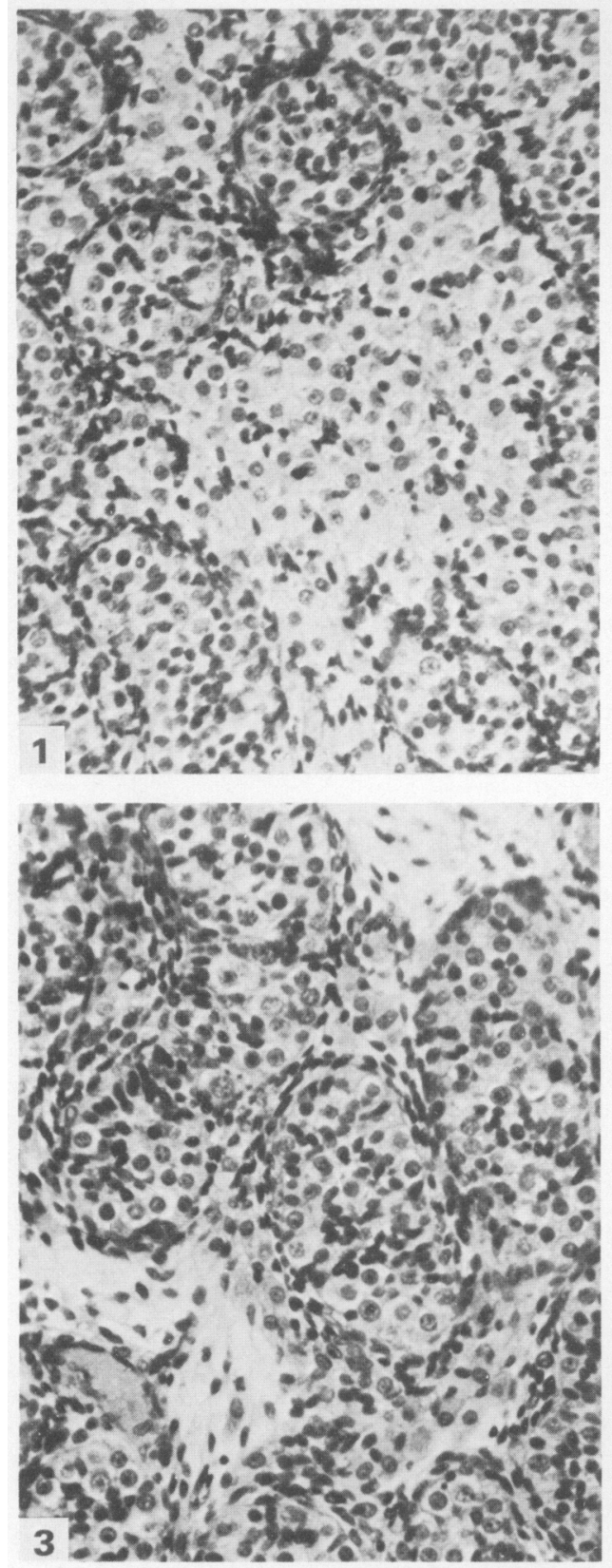
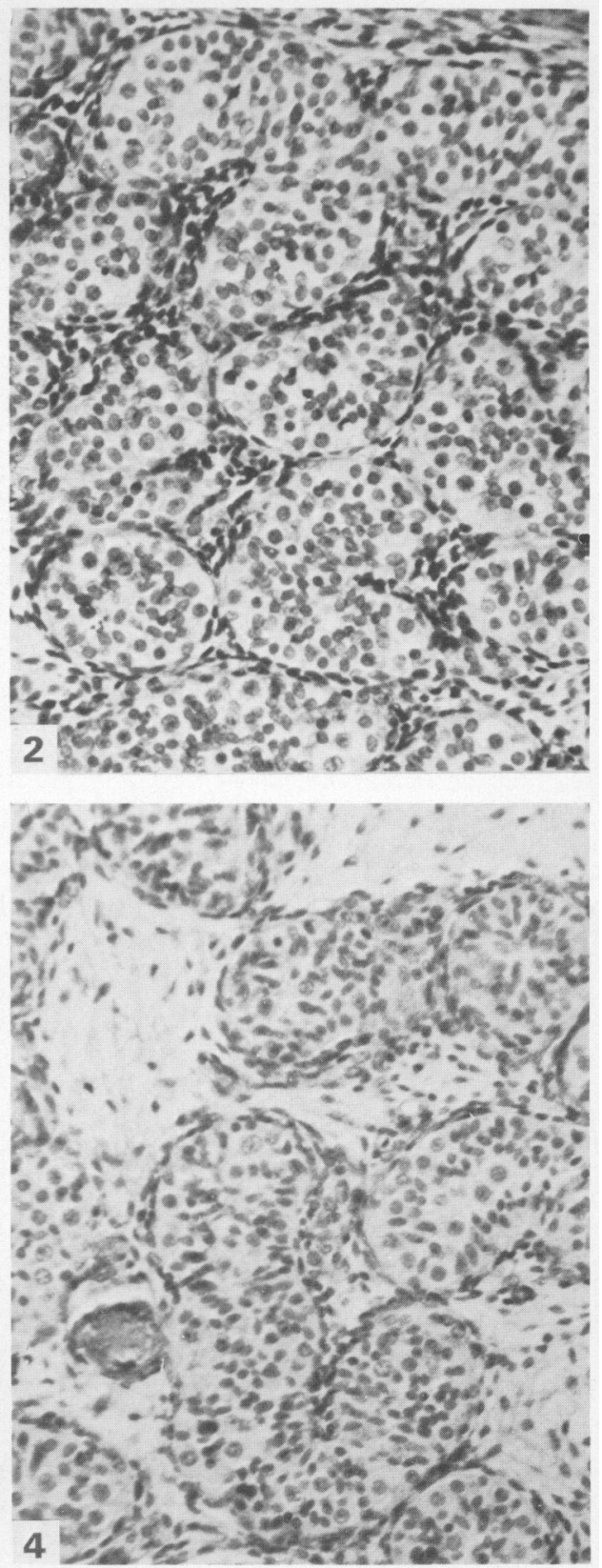

Fig. 1. Normal testis of 'a fetus at 13 weeks p.c. showing seminiferous tubules and extensive areas of Leydig tissue. $\mathrm{H} \& \mathrm{E}, \times 150$.

Fig. 2. 'Extreme' anencephalic condition in a testis of a fetus at 30 weeks of gestation. The seminiferous tubules are superficially similar to those in controls (but with fewer gonocytes) and Leydig cells are seemingly absent. $\mathrm{H} \& \mathrm{E}, \times 150$.

Fig. 3. Less extreme case of anencephaly at 28 weeks p.c. The seminiferous tubules resemble those in controls and a few Leydig cells can be seen. $\mathrm{H} \& \mathrm{E}, \times 150$.

Fig. 4. Anencephalic testis at 19 weeks p.c. showing areas of fibrous connective tissue instead of the islands of Leydig cells found in normal fetuses (compare with Fig. 1). H \& E., $\times 150$. 
PLATE 2
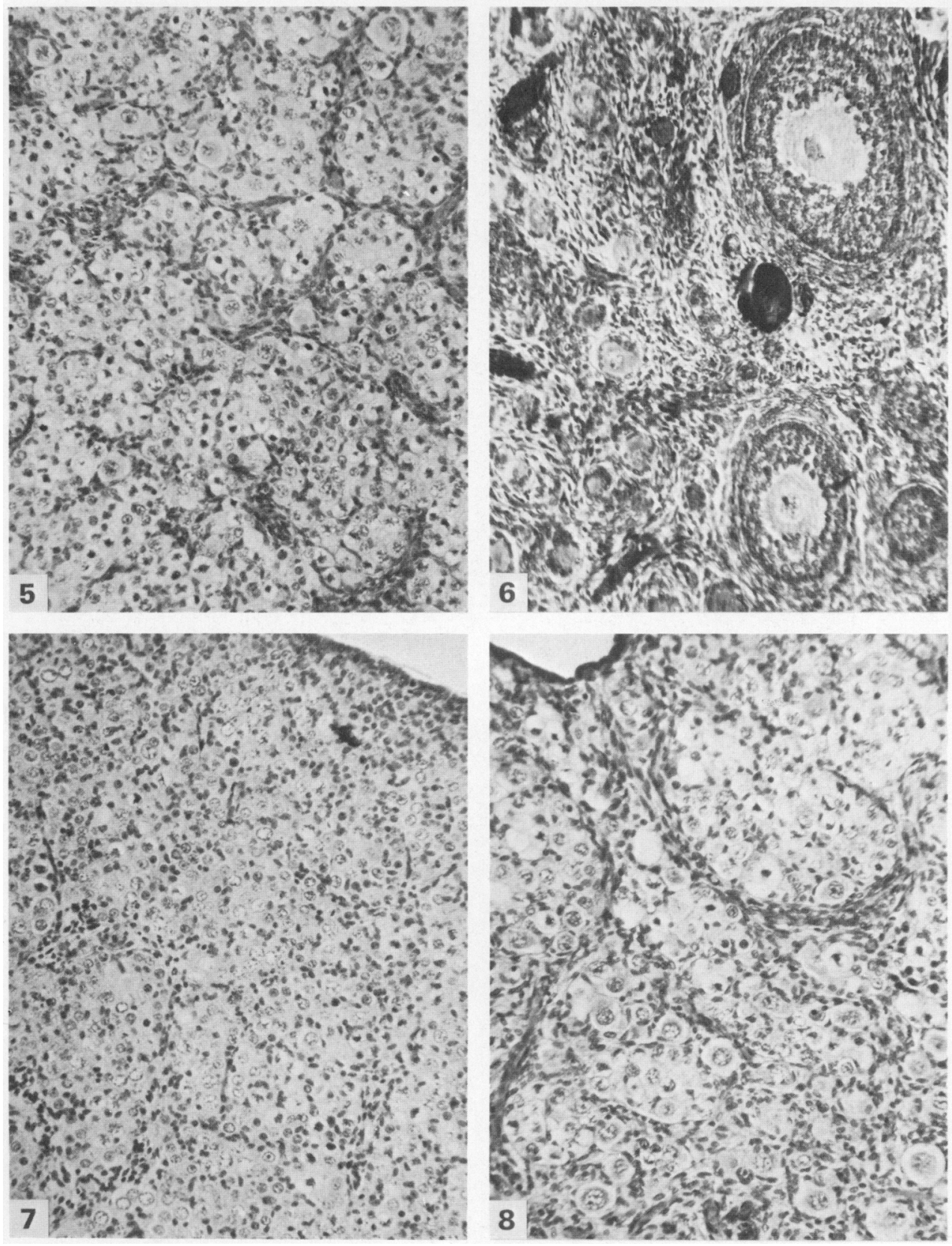

Fig. 5. Ovary recovered from a normal fetus aged 25 weeks p.c. Oogonia co-exist with oocytes at all stages of differentiation up to the diplotene stage of first meiotic prophase. $\mathrm{H} \& \mathrm{E}, \times 100$.

Fig. 6. Normal ovary at 38 weeks p.c. showing 'growing' and antral follicles at the cortico-medullary boundary. Azan, $\times 100$.

Fig. 7. Ovary of anencephalic fetus aged 10 weeks p.c. No histological differences could be detected from ovaries of coeval controls: oogonia and oocytes at the leptotene and zygotene stages of meiotic prophase can be seen. $\mathrm{H} \& \mathrm{E}, \times 100$.

Fig. 8. Ovary of anencephalic fetus at 28 weeks p.c. The stages of germ cell differentiation are almost identical to those in controls (see Fig. 5) but primordial follicles are more scattered throughout the cortex instead of forming a distinct layer near to the medulla. H \& E, $\times 100$. 

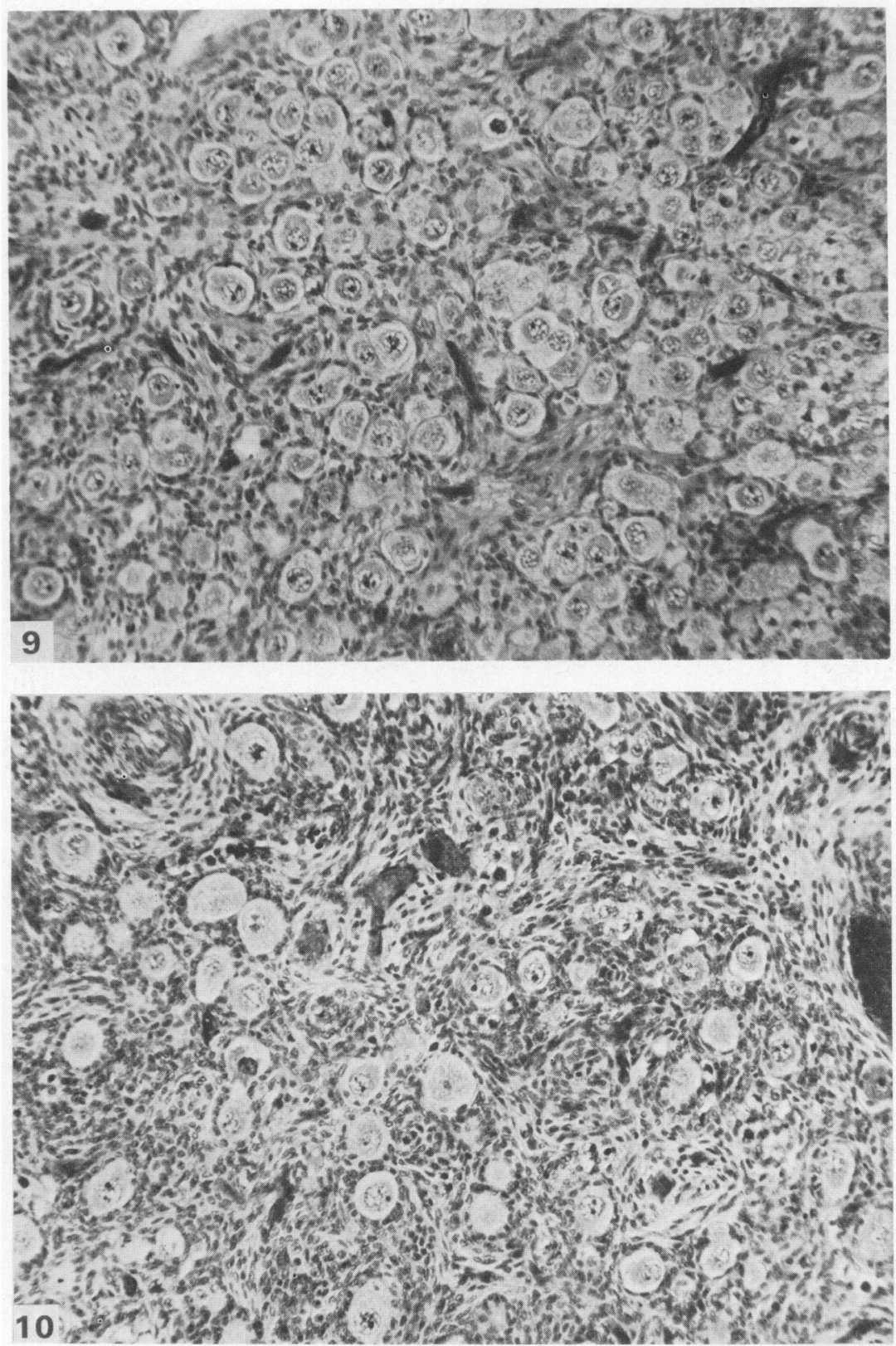

Fig. 9. Ovary of 36-week anencephalic fetus showing the ovarian cortex with normal primordial follicles and a thin rim of pre-diplotene stage oocytes. $\mathrm{H} \& \mathrm{E}, \times 100$.

Fig. 10. Ovarian medulla of the ovary shown in Fig. 9: normal single-layered primordial follicles are present but there are no "growing" and antral follicles. Compare with ovary of coeval control (Fig. 6). H \& E, $\times 100$. 
and by histochemical techniques since such cells are identified only with difficulty in ovarian sections stained with haematoxylin and eosin.

Other authors have noted the similarity in the appearance of seminiferous tubules in the testes of anencephalic and normal human fetuses (Ch'in, 1938; Zondek \& Zondek, 1965). To the best of our knowledge, however, none of the previous reports on testicular histology of anencephalic fetuses has detected a relationship between the amount of interstitial cell tissue and the number of gonocytes within the seminiferous tubules, although a similar relationship may be found in the testis after fetal hypophysectomy (Gulyas, Tullner \& Hodgen, 1977b). In the present study gonocytes were sparse when Leydig cells were seemingly absent, but the presence of even a small number of Leydig cells was accompanied by a fairly normal distribution of gonocytes per tubule. This observation is based on only 9 anencephalic fetuses and should be confirmed for a larger series of specimens and for other 'model' systems such as organ culture. Nevertheless, the reduction in the number of gonocytes is likely to be marked because the overall size of the testis (and thus of the number of cross-sections of seminiferous tubules) is greatly reduced in anencephalic fetuses (Ch'in, 1938; Zondek \& Zondek, 1965; Nakano, 1973).

The presence in anencephalic specimens of loose connective tissue where the Leydig cells would be found in controls cannot be explained at present, but it might be related to the time when the lesion affected the hypothalamus. An early lesion might prevent the formation of interstitial tissue and so leave the seminiferous tubules closely apposed, while a later lesion (occurring after extensive Leydig tissue had formed) might result in the destruction or de-differentiation of the interstitial cells with consequent fibroblastic infiltration of the spaces. This hypothesis could be tested by studying human fetal testes grown in organ culture (see Abramovich et al., 1974).

The fact that the population of Leydig cells was considerably reduced in the testes of anencephalic fetuses was surprising since earlier studies indicated that Leydig cell number and androgen production were closely correlated with the levels of hCG (Abramovich et al., 1974), at least in vitro. Women carrying anencephalic and normal babies have similar amounts of placental hCG (B. M. Hobson, unpublished observations) and the activity of the Leydig cells would therefore be expected to be comparable in the two groups. An alternative explanation, favoured by the present results, is that fetal gonadotrophin (probably FSH) is required to augment or facilitate the action of hCG crossing the placenta to the fetus. So far the only evidence in support of this view derives from studies of Leydig cell function in the ram lamb in which LH is ineffective in the absence of FSH (Courot, 1970).

The present histological observations clearly show that the proliferation of oogonia in the embryonic ovary, the progression of oocytes through meiotic prophase to the diplotene stage, and the formation of primordial follicles, occur in anencephalic fetuses in a fashion similar to that in normal fetuses. No marked changes in the total population of germ cells, the proportion of cells undergoing degeneration, or the number of oocytes at each stage in differentiation could be detected. However, the ovaries were reduced in size and hence these observations need to be confirmed by quantitative procedures.

The only histological differences detected in the present study between anencephalic and control ovaries was in the appearance and distribution of the follicles. There was a tendency for primordial follicles to be scattered throughout the cortex of anencephalic fetuses whereas in controls they were usually located at the cortico-medullary boundary. This small change was variable in extent and needs to be substantiated for more specimens aged 20-38 weeks p.c. However, the total absence of follicles with more than one layer of granulosa cells from the anencephalic specimens was in marked contrast to the situation in controls in which 'growing' and small antral follicles are consistently observed in ovaries recovered between the 32 nd week p.c. and the time of birth (Potter, 1963; van Wagenen \& Simpson, 1965; Baker, 1972b).

An absence of follicles beyond the primordial stage has also been observed in juvenile mice which had been injected with an antiserum to gonadotrophin on the day of birth: the effects of 
the antiserum could be overcome by injections of FSH and LH (Eshkol et al., 1971). Almost identical results have been obtained from studies in which mouse, hamster or human fetal ovaries were maintained in organ culture in the absence of gonadotrophic hormones: primordial follicles form normally and some of the oocytes undergo growth to a size usually found in 3-layered follicles, but the follicular epithelium is absent or defective (Baker \& Neal, 1973, 1975; Challoner, 1975a, b). When the mouse ovaries are cultured from Day 14 p.c. for 21 days (equivalent to Day 14 p.p.) in the presence of exogenous FSH or LH follicular development is at least partly restored (Baker \& Neal, 1973) and the raspberry-like clusters of oocytes are not encountered. Culture in the presence of FSH and LH results in follicles with 2-3 layers.

The evidence from the organ culture studies, and from treatment of newly born mice with antisera to gonadotrophins, indicates that FSH and LH are only required to induce follicular growth around the time of birth (probably between Days 1 and 5 p.p.). There is no evidence to suggest that gonadotrophins are required after this time for the development of the preantral follicle up to the stage $3 \mathrm{~b}$ of Pedersen (1972). The action of FSH and LH in the neonatal mouse and in the anencephalic human fetus shortly before birth may therefore be a 'trigger' to start a process which thereafter continues without hormonal control, as indicated by the fact that the early stages of follicular growth occur in hypophysectomized sexually mature mice and rats (see Ingram, 1953; Jones \& Krohn, 1961).

Hypophysectomy of the fetus in utero provides a further in-vivo model to compare with the anencephalic human fetus. However, removal of the pituitary gland affects all of the endocrine glands, results in a severe retardation in fetal growth, and in any case may not be strictly comparable to anencephaly (Honnebier \& Swaab, 1973; Gulyas et al., 1977a, b). Gulyas et al. $(1977 \mathrm{a}, \mathrm{b})$ have examined the effects on ovarian histology at full-term (168 days p.c.) of removal of the maternal pituitary gland of rhesus monkeys on Days 58-71 of pregnancy, or of the fetal pituitary on Days 114-117 p.c.. Both procedures influenced the growth of the fetus and the size of its vital organs, but maternal hypophysectomy had little effect on the histology of the ovary. By contrast, fetal hypophysectomy increased the proportion of germ cells undergoing degeneration, although the actual number of oocytes at birth was similar to that after maternal hypophysectomy (about 160000 compared with 370000 in controls). Gulyas et al. (1977b) also noted that primordial follicles form normally after hypophysectomy, but primary, 'growing' and antral follicles were considerably reduced in number (to about $2 \%$ of control value). This is in contrast to the present observations in which antral follicles were not observed in anencephalic fetuses. Nevertheless, the overall similarity between the present results, those from organ culture, and those after fetal and maternal hypophysectomy, indicates that all of the procedures provide suitable models in which to investigate the control of gonadal development and germ cell differentiation.

The expenses incurred in the present study were defrayed from grants to T.G.B. by the Ford Foundation and the Population Council. We are grateful to Dr A. D. Bain and his colleagues at the Royal Hospital for Sick Children, Edinburgh, and to Dr A. H. Cameron and his staff at the Children's Hospital, Birmingham, for assistance with the provision of the fetal gonads.

\section{References}

Abramovich, D.R., Baker, T.G. \& Neal, P. (1974) Effect of human chorionic gonadotrophin on testosterone secretion by the foetal human testis in organ culture. J. Endocr. 60, 179-185.

Baker, T.G. (1963) A quantitative and cytological study of germ cells in human ovaries. Proc. $R$. Soc. B, 158, $417-433$.
Baker, T.G. (1971) Radiosensitivity of mammalian oocytes with particular reference to the human female. Am. J. Obstet. Gynec. 110, 746-761.

Baker, T.G. (1972a) Oogenesis and ovulation. In Reproduction in Mammals, vol. 1, chapter 2, pp. 14-45. Eds C. R. Austin \& R. V. Short. Cambridge University Press. 
Baker, T.G. (1972b) Oogenesis and ovarian development. In Reproductive Biology, chapter 7, pp. 398-437. Eds H. Balin \& S. R. Glasser. Excerpta Medica, Amsterdam.

Baker, T.G. \& Neal, P. (1973) Initiation and control of meiosis and follicular growth in ovaries of the mouse. Annls Biol. anim. Biochim. Biophys. 13, 137-144.

Baker, T.G. \& Neal, P. (1975) Oogenesis in human fetal ovaries maintained in organ culture. J. Anat. 117, 591-604.

Browne, F.J. (1920) The anencephalic syndrome in relation to apituitarism. Edinburgh med. J. 25 , 296-307.

Challoner, S. (1975a) Studies of oogenesis and follicular development in the golden hamster. 2. Initiation and control of meiosis in vitro. J. Anat. 119, 149-156.

Challoner, S. (1975b) Studies of oogenesis and follicular development in the golden hamster. 3. Initiation of follicular growth in vitro. J. Anat. 119, 157-162.

Ch'in, K.Y. (1938) The endocrine glands of anencephalic foetuses. Chinese med. J., Suppl. 2, 63-90.

Courot, M. (1970) Effect of gonadotrophins on the seminiferous tubules of the immature testis. In The Human Testis, pp. 355-364. Eds E. Rosenberg \& C. A. Paulsen. Plenum Press, New York.

Elwood, J.H. (1970) Anencephalus in Belfast. Incidence and secular and seasonal variations, 1950-1966. $\mathrm{Br}$. J. Preventive \& Social Med. 24, 78-88.

Elwood, J.H. \& MacKenzie, G. (1971) Comparisons of secular and seasonal variations in the incidence of anencephalus in Belfast and Scottish cities, 19561966. Br. J. Preventive \& Social Med. 25, 17-25.

Eshkol, A., Lunenfeld, B. \& Peters, H. (1971) Ovarian development in infant mice. In Gonadotrophins and Ovarian Development, pp. 249-258. Eds W. R. Butt, A. C. Crooke \& M. Ryle. Livingstone, Edinburgh.

Franchi, L.L. \& Baker, T.G. (1973) Oogenesis and follicular growth. In Human Reproduction; Conception and Contraception, chapter 4, pp. 53-83. Eds E. S. E. Hafez \& T. N. Evans. Harper \& Row, Hagerstown.

Frandsen, V.A. \& Stakemann, G. (1961) The site of production of oestrogenic hormones in human pregnancy. Hormone excretion in pregnancy with anencephalic fetus. Acta endocr., Copenh. 38, 383391.

Gulyas, B.J., Hodgen, G.D., Tullner, W.W. \& Ross, G.T. (1977a) Effects of fetal or maternal hypophysectomy on endocrine organs and body weights in infant monkeys (Macaca mulatta); with particular emphasis on oogenesis. Biol. Reprod. 16, 216-227.
Gulyas, B.J., Tullner, W.W. \& Hodgen, G.D. (1977b) Fetal or maternal hypophysectomy in rhesus monkeys (Macaca mulatta): effects on the development of testes and other endocrine organs. Biol. Reprod. 17, 650-660.

Honnebier, W.J. \& Swaab, D.F. (1973) The influence of anencephaly upon intrauterine growth of the fetus and placenta and upon gestation length. $J$. Obstet. Gynaecol. Br. Commonw. 80, 577-588.

Ingram, D.L. (1953) The effect of hypophysectomy on the number of oocytes in the adult albino rat. $J$. Endocr. 9, 307-311.

Jones, E.C. \& Krohn, P.L. (1961) The effect of hypophysectomy on age changes in the ovary of mice. J. Endocr. 21, 497-509.

Lemire, R.J., Beckwith, J.B. \& Warkany, J. (1978) Anencephaly. Raven Press, New York.

MacMahon, B. \& McKeown, T. (1952) A note on the sex ratio in anencephalus. Br. J. Social Med. 6, 265-266.

Michie, E.A. (1966) Oestrogen levels in urine and amniotic fluid in pregnancy with live anencephalic foetus and the effects of intra-amniotic injection of sodium dehydroepiandrosterone sulphate on these levels. Acta endocr., Copenh. 51, 535-542.

Nakano, K.K. (1973) Anencephaly: a review. Develop. Med. Child Neurol. 15, 383-400.

Pedersen, T. (1972) Follicle growth in the mouse ovary. In Oogenesis, pp. 361-376. Eds J. D. Biggers \& A. W. Schuetz. University Park Press, Baltimore.

Potter, E. (1963) The ovary in infancy and childhood. In The Ovary, pp. 11-23. Eds H. G. Grady \& D. E. Smith. Williams and Wilkins, Baltimore.

Salazar, H., MacAulay, M.A., Charles D. \& Pardo, M. (1969) The human hypophysis in anencephaly. 1. Ultrastructure of the pars distalis. Arch. Pathol. 87, 201-211.

van Wagenen, G. \& Simpson, M.E. (1965) Embryology of the Ovary and Testis in Homo sapiens and Macaca mulatta. Yale University Press, New Haven.

Zondek, L.H. \& Zondek, T. (1965) Observations on the testis in anencephaly with special reference to the Leydig cells. Biol. Neonate 8, 329-347.

Zuckerman, S. \& Baker, T.G. (1977) The development of the ovary and the process of oogenesis. In The Ovary, 2nd edn, vol. 1, chapter 2, pp. 41-67. Eds S. Zuckerman \& B. J. Weir. Academic Press, New York.

Received 28 February 1980 